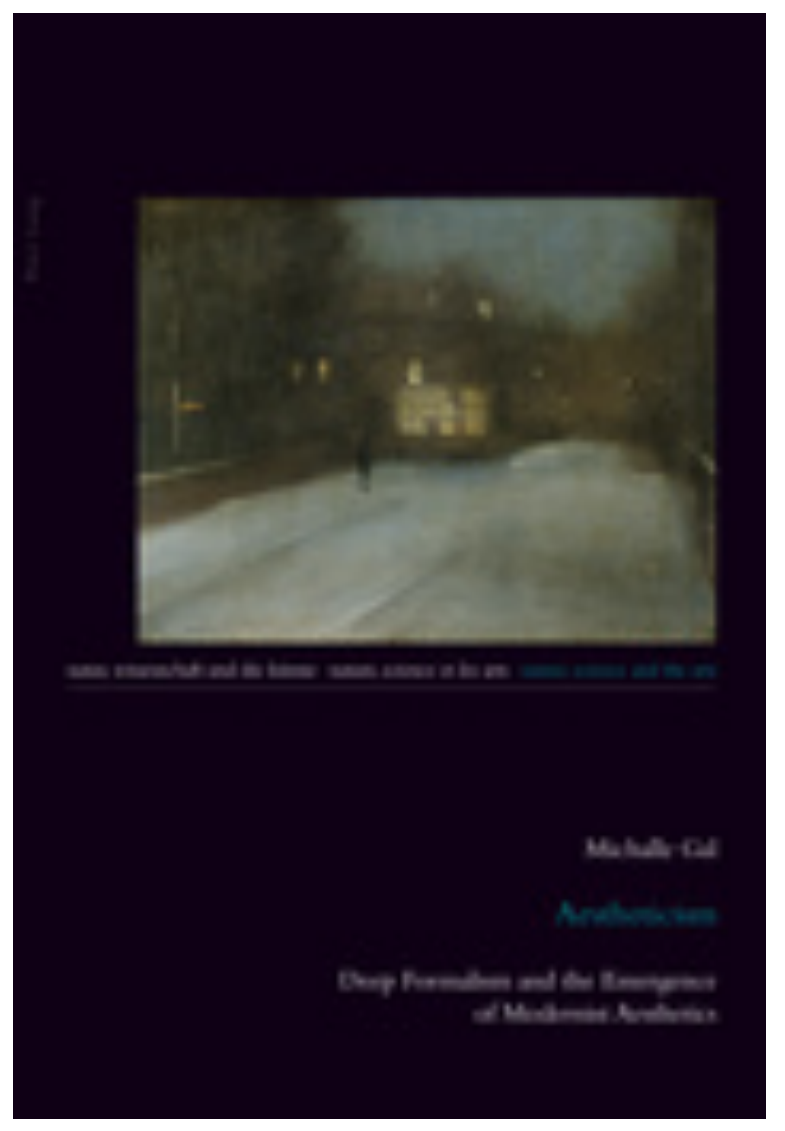

\title{
Aestheticism. Deep Formalism and the Emergence of Modernist Aesthetics
}

\author{
Michalle GAL
}

El lector encontrará en este ensayo de Michalle Gal una reconstrucción de los principios estéticos de la corriente designada por la autora como "formalismo profundo" (deep formalism); reconstrucción realizada a partir del contraste con las corrientes estéticas que lo anteceden - tomando como referente el realismo de John Ruskin, tanto en su faceta de escritor, como en su faceta de pintor y crítico de arte - y suceden - ejemplificadas en corrientes artísticas como el pop art, el arte conceptual, de performance o de instalaciones, así como en las teorías de Arthur C. Danto -. La descripción que la autora realiza de los principios del formalismo profundo se realiza, por tanto, de forma negativa, a través de la comparación con el fundamento del arte tal y como es concebido en estas últimas teorías y corrientes; a saber: el arte como mímesis, ya sea bajo la forma de la imitación natural de los objetos mentados en la obra, ya sea como imitación de un concepto externo a la misma. Los siete capítulos que integran el ensayo constituyen así un insistente "ajuste de cuentas" con la restricción de la autonomía del arte y su conversión en un medio al servicio de la expresión, ya sea de contenidos externos a la obra y evocados en la misma, ya sea de un concepto que explique y justifique la obra confiriéndole sentido. Justamente en la noción de expresión se concentra la crítica a la estructura de la obra como compuesto separado de materia y forma, como si la forma pudiera separarse del contenido y yuxtaponerse a 
unas preconcepciones anteriores a la obra - por tanto como si fuera posible expresar un mismo contenido en diferentes medios artísticos, traduciéndolo de unas manifestaciones artísticas a otras. A lo largo del ensayo, Gal perfilará la crítica a la constricción de la libertad característica de la obra de arte que se efectúa en el arte entendido como mímesis, dado que en él la creación artística es un mero medio al servicio de la expresión de un contenido externo a la misma. En esta crítica opondrá, frente a la separación entre materia y forma que caracteriza al simbolismo premoderno, el carácter incrustado que adquiere la forma en el formalismo profundo, de manera que, según este último, no cabrá realizar ninguna abstracción de contenido respecto de la forma. Encontramos en esta distinción una división del concepto de interpretación de la obra de arte dependiendo de si dicha interpretación atiende al elemento semántico de la misma o al recorrido de su sintaxis estructural. En el primero de los casos nos hallamos ante la búsqueda de un contenido exterior a la obra; en el segundo, la referencia de la obra de arte es el resultado del recorrido de esta estructura realizado por el artista, intérprete y espectador. A pesar de que Gal se apoya en la distinción entre semántica y sintaxis para explicar el paso de un modelo representacional a un modelo construccionista, propio del formalismo profundo, observamos cómo la propuesta de atender a la sintaxis interna de la obra no elimina la referencialidad de la misma: en toda obra artística seguirá existiendo algo mentado en la misma, si bien este tema o referencia no será ya considerada como preexistente y luego expresada en la obra, sino como el resultado del propio proceso por el cual se recorre la estructura de la obra. La pregunta acerca del proceso de formación de esta referencia producida en la obra de arte se disuelve en la insistente dicotomía entre semántica y sintaxis que nos plantea M. Gal. El lector entenderá, atendiendo a los repetidos avisos de la autora, que plantear siquiera la pregunta, es decir, insistir en el objeto producido en el cuadro como entidad reconocible e identificable, más allá de la sucesión de los momentos que componen su estructura interna, supone añadir a la contemplación estética de la obra una actividad interrogativa de pregunta acerca del sentido, como si esta pregunta pudiera plantearse más allá de los límites del cuadro. La actitud estética consistirá entonces en un abandono de cualquier ejercicio de autoridad sobre la obra, de manera que el sujeto quede liberado frente al ejercicio de poder característico de la actitud teórica, tal como se insinúa en las páginas finales de este ensayo recordando las palabras de Wilde: "the moment he (the spectator) seeks to exercise authority, he becomes the avowed enemy of Art, and of himself. Art does not mind. It is he who suffers".

La pregunta acerca de la constitución del objeto mentado en la obra de arte permanece, por tanto, sin resolver y en sí misma cancelada. Por medio del concepto de "opacidad productiva", Gal alude al carácter cerrado del símbolo artístico, que mueve a descubrir su estructura interna sin poder reconducirla al ámbito de lo natural, de la experiencia cotidiana. La oposición naturaleza/artificio se resuelve en la corriente del formalismo profundo no al modo de la imitación de lo natural, sino del reconocimiento de la imperfección de la naturaleza frente al diseño de la obra de arte como unidad completa (E. M. Forster). Ante la incompletitud del orden natural, la obra de arte puede ser observada como una totalidad cerrada, opaca por tanto respecto de la realidad externa en la que se sitúa el espectador. Debido a esta estructura, al cierre de cada obra en los límites del marco, se abandona la referencia a una realidad exterior que sirva como modelo para la creación, así como la referencia a conceptos o ideas generales que trasciendan su marco. Permanece latente en el discurso de Gal - un discurso por lo general extraño a la "explicación" o la "justificación" de lo que no ha de ser sino descrito - la pregunta acerca de la necesidad de recorrer la forma que articula la obra artística, su sintaxis, dado que al entenderse la obra como una 
totalidad cerrada no habría en principio razones para excluir la aprehensión inmediata del referente creado en la obra. En este sentido, autores desligados de esta corriente como Greenberg, niegan que la obra de arte tenga una direccionalidad interna vinculada a la historicidad de su proceso de gestación. Si bien la argumentación de M. Gal insiste en la idea de entender el referente de la obra como el resultado de un proceso y no como una idea previamente dada, no resulta del todo clara la explicación de este carácter procesual de la creación del referente mediante la apelación a la opacidad constitutiva de la obra. Si en efecto la obra de arte consiste en una totalidad ontológicamente cerrada, ¿no garantiza la unidad cerrada por los límites del cuadro el que el objeto referido pueda ser aprehendido de una vez? ¿No son los límites establecidos por el marco los que garantizan la unidad del tema de la obra? Para entender el papel del recorrido de la sintaxis presente en la obra de arte, habrá que acudir al tipo de arte al que Gal recurre para explicar la recepción de la obra en el formalismo profundo : la música. Es gracias a la dispersión de las unidades que componen la melodía en el tiempo por lo que la referencia de la obra es el resultado del proceso que realizan autor y receptor. De ahí, que para caracterizar a las artes pictóricas propias del formalismo profundo, el principio fundamental sea: como la música, la imagen pictórica. Dado que en la música se da la perfecta unión de materia y forma (según W. Pater), que permite identificar la sintaxis de la obra con la articulación específica de determinados contenidos, el arte pictórico tomará a la música como el modelo que explique su proceso de creación y crítica.

Con este armazón teórico, M. Gal detalla la propuesta del formalismo profundo, encarnada en corrientes como el esteticismo y el arte postimpresionista y presente en autores procedentes del campo pictórico (la serie Nocturnes de Whistler, la obra de Matisse), literario (Wilde), así como en la historia y crítica de artede Walter Pater, quien sugerirá la existencia de una razón sensualista o razón imaginativa que perciba el contenido en su despliegue temporal siguiendo la sintaxis de la obra, con un planteamiento que recuerda al papel atribuido por Kant a la imaginación en la Crítica de la razón pura. Para subrayar el carácter original y creador de la obra de arte en relación al resto de artefactos creados por el hombre, justamente por tratarse de un artificio aislado respecto del resto de elementos que integran el contexto en el cual el espectador recibe la obra, Gal se apoya en las anotaciones de Fry y Clive Bell.

Otro de los aspectos que permanecen sin aclarar en este ensayo es la presunta pertenencia de la actividad de crítica artística a la propia estructura constitutiva de la obra. Al enfrentar la crítica a la interpretación, de manera que en la segunda se repite el ideal mimético de asignación de determinadas ideas o conceptos ajenos a la obra para la explicación de la misma, Gal sitúa a la crítica como una actividad análoga al proceso de creación, como si la crítica constituyera a su vez la forma profunda que toma como materia a la obra de arte. Asumiendo la inseparabilidad de la forma respecto de la materia y la necesaria articulación de la materia conforme a la sintaxis formal que le es propia, la tesis de Gal conllevaría la consideración de la crítica como una suerte de metaestructura que vertebra a la obra constituyendo con ella una misma unidad. Con ello nos enfrentamos a la pregunta inevitable acerca del carácter concreto de esta crítica: ¿se trata fundamentalmente de una actividad literaria? Surgiría de nuevo la cuestión acerca de la coexistencia de diferentes niveles artísticos (literario, visual, etc.) dentro de la misma obra y sería posible aplicar aquí la objeción planteada a las corrientes posteriores al "giro lingüístico" como el pop art, la instalación, la performance o el arte conceptual, en las cuales la diferencia entre las artes visuales y literarias queda disuelta. Pero quizá aquí como en otros pasajes se constata un procedimiento habitual en la argumentación de Gal: la crítica será igual a 
la actividad artística en cierto sentido, esto es, en su actitud de tomar como materia a la obra de arte misma como una unidad cerrada sin tratar de interpretarla conforme a modelos teóricos previamente asumidos. Pero con ello no tomará en consideración el resto de consecuencias que se derivan de tomar a la crítica como una forma de arte más: la posibilidad de que la obra y su crítica constituyan una unidad indisoluble, presuntamente compuesta por diferentes medios artísticos (visual, literario, etc); la posibilidad de que la crítica sea una forma de segundo orden, incrustada en la obra y ofreciéndole una sintaxis específica; etc.

Acompañando a las dudas que seguramente asalten al lector, Gal se preguntará finalmente las posibles razones de la desaparición de esta corriente esteticista, caída que anuló la autonomía del arte devolviéndolo a su función imitativa, si bien ahora entendida como mímesis conceptual. También surgirá la sospecha acerca de la aceptabilidad y adaptabilidad de las obras propias de esta corriente al gran público, ¿es accesible la renuncia a la mímesis para la mayoría? ¿no habrá resistencias a interpretar la obra conforme a determinados valores éticos, sociales, políticos, etc. extendiendo la actitud valorativa que los espectadores realizan habitualmente en su vida cotidiana? ¿puede la actitud pasiva liberadora de entregarse por completo al despliegue de la obra en su estructura interna ser una actividad al alcance de la mayoría? Estas dudas acompañarán a los interrogantes que resulten de una explicación de la condición ontológica de la obra de arte en el esteticismo que mueve a la reflexión sin ofrecer conclusiones definitivas.

Ficha técnica del libro:

\begin{tabular}{r|l} 
Título: & $\begin{array}{l}\text { Aestheticism . Deep Formalism and the } \\
\text { Emergence of Modernist Aesthetics }\end{array}$ \\
Autor: & Michalle GAL \\
Editorial: & New York, Peter Lang Publishers, 2015. \\
Número de páginas: & 164
\end{tabular}

María Teresa Álvarez MATEOS 